\title{
On the Chemistry of Cigar Smoke: Comparisons between Experimental Little and Large Cigars*
}

\author{
by \\ Irwin Schmeltz, Klaus D. Brunnemann and Dietrich Hoffmann \\ American Health Foundation, Valhalla, N. Y., U.S.A. \\ and \\ Alan Cornell \\ Consolidated Cigar Corporation, Glastonbury, Conn., U.S.A.
}

\section{INTRODUCTION}

The objective of the study to be described, i. e. to examine the smoke of little and large cigars, represents a part of our continuing effort to determine the parameters influencing smoke composition. Parameters which are likely to play a role are physical design of the cigar, leaf type and composition, and wrapper type (porous vs. non-porous). As in other correlative studies, the goal is to predict smoke composition on the basis of given properties of a smoking product and ultimately to devise a product with modified smoke composition in which undesirable constituents are reduced. This has been achieved to a large extent by various techniques at least for some cigarettes $(I-6)$. However, unlike cigarettes, cigars have been the subject of relatively limited study in areas such as smoke composition (7-11), effect of leaf type (12), and other factors (13) on such composition, and on similarities and differences between cigars and cigarettes (14 - 16). The present study is an attempt to gain more insight into the composition of cigar smoke and the factors influencing it.

Two basic types of cigars were chosen for this investigation. Some of the physical features of these are given in Table 1. The little cigars were subdivided into two groups, each group being identical except for the wrapper type. The first group was wrapped in conventional cigar wrapper, the second in cigarette paper, thus allowing a demonstration of the effects of wrapper type on smoke composition. One of five different tobaccos was utilized as filler in each cigar fabricated; there were no blends. The filler tobaccos used in the large cigars were cigar scrap cut, those in the little cigars were shredded filler. Overall, then, there were three groups of five cigars each; the first two groups differed mainly in wrapper type; the third group was identical to the first group except for size and presence of binder. Chemical analyses were performed on both

\footnotetext{
"No. XLV of "Chemical Studies on Tobacco Smoke". Presented in part at the 29th Tobacco Chemists' Research Conference, University of Maryland, College Park, Md., Oct. 8-10, 1975.
}

Table 1. Clgar types compared.

\section{Little clgare}

$85 \mathrm{~mm}$; non-filter; diameter: $8.0 \mathrm{~mm}$; weight: $1.0 \mathrm{~g}$. No binder.

1 - With cigar wrapper (RTS)*

II - With cigarette paper

\section{Large clgars}

$135 \mathrm{~mm}$; non-filter; diameter: $13.0 \mathrm{~mm}$; wejght: $7.0 \mathrm{~g}$. III - With cigar wrapper (RTS) and binder (RTS, Binder Formulation)

\section{Tobaccos}

Puerto-Rico, Manila, Colombia, Domingo-Criollo, Pennsylvania.

- RTS - Reconstituted tobacco sheet.

leaf and smoke. The factors and constituents considered in the present report are itemized in Table 2.

The analytical data lead to a search for correlations among the various constituents in both leaf and smoke. At present, even without the aid of computer analysis, the data indicate certain trends among various components, and reveal rather interesting differences between little and large cigars.

\section{Table 2. Analyses.}

Leaf constituents

Water,

Nicotine,

Nornicotine,

Reducing sugars,

Hexane-solubles,

Neophytadiene,

Nitrate.

Clgar characteristlcs

Draw resistance,

Burning rate,

Puff number.

\section{Smoke consiltuents}

pH

"Tar":

TPM,

Water,

Nicotine,

Benzo(a)pyrene, Volatile phenols, Pyridines.

Gas phase:

Co, Isoprene,

$\mathrm{CO}_{2}$ Acetaldehyde,

$\mathrm{NH}_{3}$ Acrolein. 


\section{EXPERIMENTAL}

Details of the methods used are presented in the references cited; otherwise, they are given below:

Cigar selection, and determination of average weights $(29,35)$

Static burning rate and pressure drop (29)

Total particulate matter (TPM) and smoking conditions $(17,18,36,37)$

Moisture in TPM $(31,37)$

Nicotine in smoke $(17,29,35,36)$

Volatile phenols (29)

pH of mainstream smoke $(20,21)$

Benzo(a)pyrene in smoke [as indicator for yield of PAH (22)]

\section{$\mathrm{CO}$ and $\mathrm{CO}_{2}$ (23)}

\section{Moisture in cigar tobaccos (32)}

Tobacco $(10-20 \mathrm{~g})$ was ground in a blender and placed in a distilling flask, $200 \mathrm{ml}$ xylene was added and the mixture distilled into a Dean-Stark trap. After 8 hours, the volume of water in the Dean-Stark trap was measured.

Ammonia in smoke (24)

Gas phase: isoprene, acrolein and acetaldehyde $(15,16$, 25)

Pyridines in smoke $(26,27)$

Nornicotine in leaf (30)

Hexane-Extractables and Neophytadiene from Cigar Tobaccos

Cigar tobacco ( 40 - $50 \mathrm{~g}$ ) was extracted by refluxing with $\mathrm{n}$-hexane $(250 \mathrm{ml})$ for 16 hours. The hexane solution was then dried over sodium sulfate and evaporated to dryness. Residue weights were then determined. Neophytadiene was determined by gas chromatography, injecting an aliquot of the hexane solution into a $2 \mathrm{~m} \times 2 \mathrm{~mm}$ (i. d.) glass column, $10 \%$ UC-W 98 (on Gaschrom Q, $80-100$ mesh) at $180^{\circ} \mathrm{C}$, with a He flow rate of $55 \mathrm{ml} / \mathrm{min}$; injector and detector were set at $240^{\circ} \mathrm{C}$. Neophytadiene had a retention time of 7.5 minutes.

\section{Leaf Nicotine}

Cigar tobacco was ground, and approximately $1 \mathrm{~g}$, accurately weighed, was placed in a distilling flask to which ${ }^{14} \mathrm{C}$-nicotine was added as internal standard. Twenty $\mathrm{ml}$ of $10 \% \mathrm{NaOH}$ was also added, and the mixture was steam distilled. The distillate, $500 \mathrm{ml}$, was trapped in $2 \mathrm{~N} \mathrm{H}_{2} \mathrm{SO}_{4}$. The solution was basified and extracted with ether; the ether solution was dried $\left(\mathrm{Na}_{2} \mathrm{SO}_{4}\right)$ and concentrated to $1.0 \mathrm{ml}$. An aliquot was analyzed by gas-liquid chromatography using a $2 \mathrm{~m}$ $X 0.32 \mathrm{~cm}$ stainless steel column packed with $10 \%$ UC-W 98 on silylated Chromosorb W (80 - 100 mesh). The conditions were: column, $150^{\circ} \mathrm{C}$; injector, $235^{\circ} \mathrm{C}$; FI-detector, $240^{\circ} \mathrm{C}$; helium flow, $40 \mathrm{ml} /$ minute. The retention time of nicotine was 6.9 minutes.

\section{RESULTS AND DISCUSSION}

Leaf: Levels of various leaf constituents are given in Table 3. Examination of the data shows that Puerto Rico type cigar tobacco, of those listed, contains the highest level of nicotine, and the lowest level of neophytadiene; Colombia cigar tobacco, on the other hand, is lowest in nicotine and highest in neophytadiene. This observation may be a consequence of compositional differences in tobacco varieties and may also be indicative of changes occurring in the leaf during processing (e. g. fermentation) where nicotine levels decrease dramatically relative to other leaf constituents (33). The same relation appears to hold true for the hexane-solubles and nicotine as well; neophytadiene, of course, is part of the hexane-solubles, and levels of these parallel each other. As for the other values, as expected, reducing sugars are low $(15,33)$ and nitrate is at relatively high levels when compared to cigarettetype tobaccos [except perhaps for Burley and Maryland cigarette tobaccos $(3,33,34)$ ]. Ranges of values among the different cigar tobaccos, for given constituents, do not show much variation - as often occurs between different tobacco types.

Cigar Characteristics: Prior to smoke analysis, the physical characteristics, i. e. weight, puff number, and pressure drop for the three groups of cigars were

Table 3. Clgar tobaccos: Concentration levels of various constituents* $(\%)$.

\begin{tabular}{|c|c|c|c|c|c|c|c|}
\hline Type & $\mathrm{H}_{2} \mathrm{O}$ & $\begin{array}{l}\text { Hexane- } \\
\text { solubles }\end{array}$ & $\begin{array}{c}\text { Neo- } \\
\text { phytadiene }\end{array}$ & Nicotine & $\underset{\text { Nor- }}{\text { nicotine }}$ & $\begin{array}{l}\text { Reducing } \\
\text { sugars }\end{array}$ & $\mathrm{NO}_{3} * *$ \\
\hline Puerto-Rico & 12.7 & 4.5 & 0.46 & 1.7 & 0.16 & 0.45 & 1.78 \\
\hline Manila & 11.7 & 5.2 & 0.48 & 0.9 & 0.15 & 0.44 & 1.27 \\
\hline Colombia & 11.6 & 8.1 & 0.77 & 0.6 & 0.09 & 0.37 & 2.53 \\
\hline Domingo-Criollo & 10.6 & 6.3 & 0.65 & 1.1 & 0.19 & 0.40 & 1.40 \\
\hline Pennsylvania & 13.7 & 5.1 & 0.56 & 1.2 & 0.08 & 0.37 & 1.60 \\
\hline
\end{tabular}

- Dry welghtbasis.

*" Method of H. Jacin: Tobacco Science 14 (1970) 28-30; methods for other constituents given in experimental section. 
Table 4. Clgar characteristicsa.

\begin{tabular}{|c|c|c|c|c|c|c|c|c|c|}
\hline \multirow{2}{*}{ Filler } & \multicolumn{3}{|c|}{$\begin{array}{l}\text { Weight } \\
\text { (g) }\end{array}$} & \multicolumn{3}{|c|}{$\begin{array}{l}\text { Puff rate } \\
\text { (no./cig.) }\end{array}$} & \multicolumn{3}{|c|}{$\begin{array}{l}\text { Pressure drop } \\
\left(\mathrm{mm} \mathrm{H}_{2} \mathrm{O}\right)\end{array}$} \\
\hline & 1 & II & III & 1 & II & III & 1 & II & III \\
\hline Puerto-Rico & 1.1 & 1.0 & 6.4 & 8.9 & 10.4 & 68.0 & 59 & 45 & 54 \\
\hline Manila & 1.0 & 1.0 & 6.8 & 8.4 & 9.0 & 73.0 & 41 & 41 & 54 \\
\hline Colombia & 1.1 & 1.1 & 6.8 & 8.6 & 10.3 & 69.5 & 59 & 53 & 54 \\
\hline Domingo-Criollo & 1.1 & 1.0 & 6.8 & 8.5 & 9.6 & 74.0 & 46 & 40 & 61 \\
\hline Pennsylvania & 1.0 & 0.9 & 6.8 & 7.9 & 7.5 & 66.8 & 45 & 27 & 59 \\
\hline Averages & 1.1 & 1.0 & 6.7 & 8.5 & 9.4 & 70.3 & 50 & 41 & 56 \\
\hline
\end{tabular}

Key: I: Little cigar, clgar wrapper, II: Little cigar, paper wrapper, III: Large cigar.

a: Burning rates were obtained only for the little cigars, as the large cigars did not stay lit under "free burn" conditions.

For the little cigars, values were $(\mathrm{mg} / \mathrm{m} / \mathrm{n})$ 65.1, 67.2, 74.5, 65.6, 79.0 for group I and 48.8, 50.8, 58.4, 48.5, 59.4 for group II.

determined and are given in Table 4. As already noted, the weights of the large cigars are nearly seven times those of the little cigars. Interestingly, the pressure drop, measured as $\mathrm{mm} \mathrm{H}_{2} \mathrm{O}$, does not differ significantly among the three groups of cigars. Note that the large cigar has 8 to 9 times the puff number as the little cigar. It should be mentioned that the little cigars were smoked for the most part using standard cigarette conditions, whereas the large cigars were smoked according to the cigar smoking schedule (Table 5). Justification for use of the two different

Table 5. Smoking protocol.

\begin{tabular}{lc|c}
\cline { 2 - 3 } & $\begin{array}{c}\text { Cigarette } \\
(17,29,35)^{*}\end{array}$ & $\begin{array}{c}\text { Cigar } \\
(18)\end{array}$ \\
\hline Puff volume (ml) & 35 & 20 \\
Puff duration (s) & 2 & 1.5 \\
Puff interval (s) & 60 & 40 \\
Butt length (mm) & 23 & 33 \\
\hline
\end{tabular}

"Often referred to as "standard smoking conditions".

smoking protocols lay in the premise of approximating conditions for the smokers of little cigars, which are more like those for cigarette smokers versus conditions for smokers of large cigars. Therefore, when comparing smoke constituents on a per cigar basis, we try to evaluate smoke levels as the smoker experiences them. However, to equate comparisons on a chemical analytical basis, we also converted the data to quantities per puff, and quantities per liter of smoke.

Smoke Analysis: Considering now the question of smoke composition, we note in Table 6 levels of the principal smoke constituents (i. e. TPM, nicotine and benzo[a]pyrene) delivered by the three groups of cigars. There are two comparisons to be made here first between the little cigars with different wrappers, and then between the cigars of different sizes. The data for TPM, nicotine, and benzo(a)pyrene (BaP) suggest that a more porous paper (or wrapper) has little, if any, effect on concentration levels of these smoke constituents. It must be realized though that with a more porous wrapper a proportionately smaller volume of the $35 \mathrm{ml}$ puff is drawn through the burning cone of the little cigar than is the case for a little cigar with less porous cigar wrapper. This has at least two effects; namely, the little cigar with cigarette paper burns slower during the actual puffing, thus the combustion is somewhat more complete (less oxygen deficient), and, as a result, smoking a given tobacco column requires more puffs. Both factors, more complete combustion and greater number of puffs, have a compensating effect on the TPM and BaP formation.

Table 6. Smoke* constituents: Little vs. large cigars.

\begin{tabular}{|c|c|c|c|c|c|c|c|c|c|}
\hline \multirow{2}{*}{ Tobacco } & \multicolumn{3}{|c|}{ TPM $(\mathrm{mg})^{* *}$} & \multicolumn{3}{|c|}{ Nicotine (mg) } & \multicolumn{3}{|c|}{$\mathrm{BaP}$ (ng) } \\
\hline & I & 11 & III & 1 & II & III & 1 & II & III \\
\hline 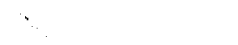 & \multicolumn{9}{|c|}{ (quantities/cigar) } \\
\hline Puerto-Rico & 41.1 & 38.9 & 28.0 & 2.7 & 2.9 & 2.8 & 61.3 & 47.8 & 10.8 \\
\hline Manila & 31.6 & 31.8 & 36.8 & 1.4 & 1.5 & 1.8 & 24.1 & 23.9 & 36.9 \\
\hline Colombia & 33.3 & 37.6 & 39.0 & 0.7 & 0.8 & 1.7 & 36.5 & 43.5 & 28.3 \\
\hline Domingo-Criollo & 31.4 & 38.5 & 36.9 & 1.6 & 1.6 & 2.6 & 26.9 & 50.1 & 17.9 \\
\hline Pennsylvania & 29.3 & 32.5 & 34.7 & 1.4 & 1.3 & 3.2 & 18.8 & 35.8 & 17.7 \\
\hline Averages & 33.3 & 35.9 & 35.1 & 1.6 & 1.6 & 2.4 & 33.5 & 40.2 & 22.3 \\
\hline
\end{tabular}

Key: I: Little clgar, clgar wrapper, II: Little clgar, paper wrapper, III: Large cigar.

- Mainstream.

* Federal Trade Commission value for TPM = wet TPM minus water and minus nicotine. 
Table 7. Smoke* constituents: Little vs. large clgars.

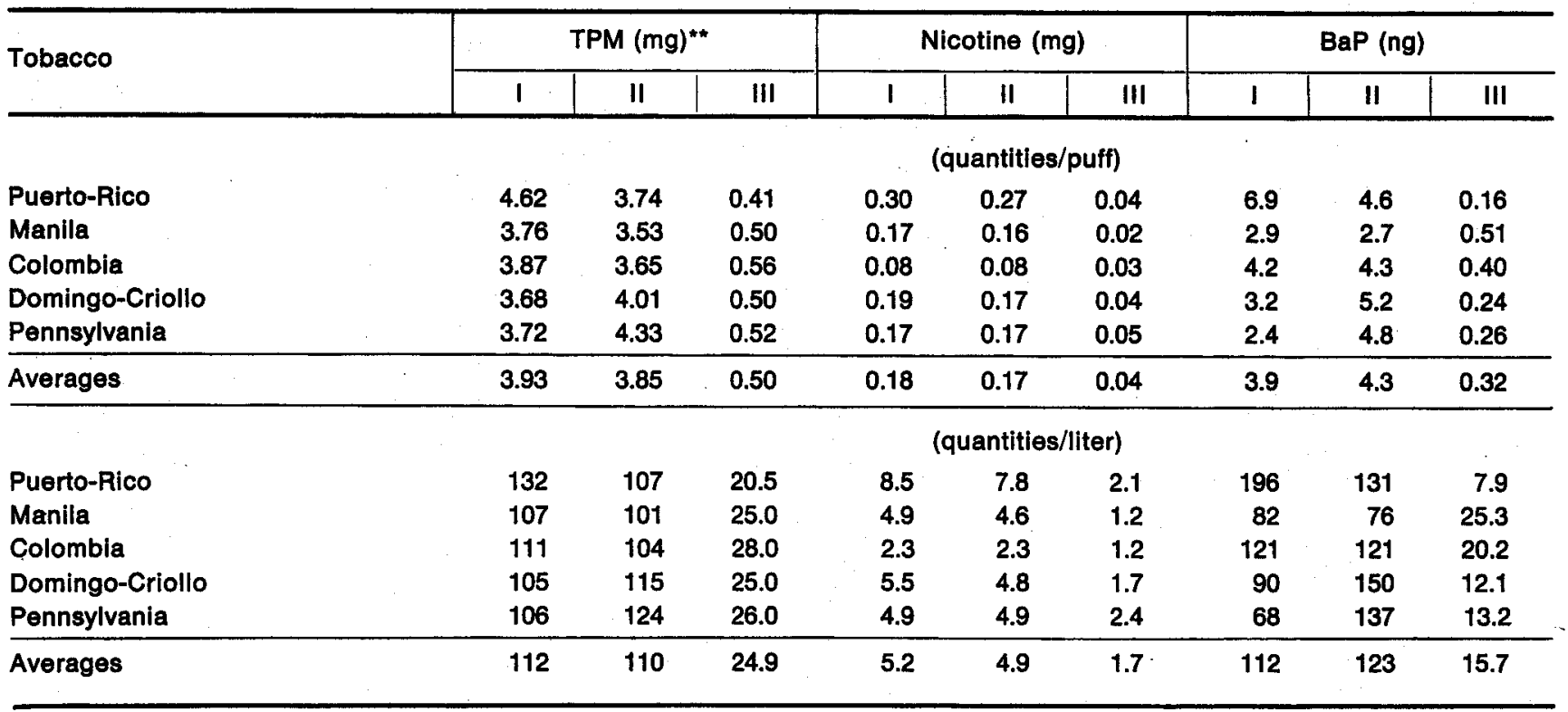

Key: I: Little clgar, clgar wrapper, II: Little clgar, paper, wrapper, III: Large elgar.

* Mainstream.

"* Federal Trade Commisslon value for TPM = wet TPM minus water and minus nicotine.

More interesting, perhaps, is the comparison of the large and little cigars. The large cigars weigh nearly seven times more than the little cigars; however, this large weight difference is not reflected in the levels of TPM, nicotine and BaP generated, inter alia. In a number of instances, even lower levels of these constituents are generated by the large cigars than by the corresponding little cigars. The data shown are on a per cigar basis (Table 6), and the cigars were smoked by different protocols, as indicated before. However, this alone could not account for the results observed. To gain another perspective, and to perhaps make more appropriate comparisons, the data were converted to a per puff and a per liter of smoke basis. These data, shown in Table 7 , emphasize even more the differences between the mainstream smoke of little and large cigars. On a per puff scale, for example,
TPM, nicotine and BaP delivered by the large cigars are, on the average, one-seventh, one-third and about one-tenth that delivered by the little cigars. In reviewing these observations, consideration should be given to the effect of air flow rate over the coal on completeness of combustion as the smoking regimen is changed. Again, as far as the individual smoker is concerned, what is relevant are the quantities of smoke constituents generated per cigar. As noted in Table 6, smokers of little or large cigars "see" approximately the same levels of TPM, nicotine and BaP - the question of inhalation, of course, enters considerations of exposure in this case.

The correlation between nicotine levels in leaf and smoke is especially true for the little cigars, and less so for the large cigars. The transfer rates of nicotine into mainstream smoke are markedly different for the

Table 8. Volatlle phenols and pyridines in cigar smoke ( $\mu \mathrm{g} / \mathrm{clgar})$.

\begin{tabular}{|c|c|c|c|c|c|c|c|c|c|c|c|c|}
\hline \multirow[t]{2}{*}{ 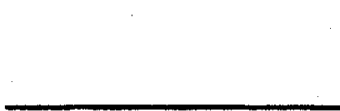 } & \multicolumn{3}{|c|}{ Phenol } & \multicolumn{3}{|c|}{ Total phenolsa } & \multicolumn{3}{|c|}{ Pyridine } & \multicolumn{3}{|c|}{ Total pyridinesb } \\
\hline & 1 & II & III & 1 & II & III & 1 & II & III & 1 & 11 & III \\
\hline Puerto-Rico & 164 & 166 & 375 & 301 & 287 & 527 & 99 & 141 & 647 & 317 & 456 & 996 \\
\hline Manila & 166 & 171 & 398 & 329 & 360 & 782 & 100 & 108 & 518 & 325 & 428 & 768 \\
\hline Colombia & 101 & 145 & 367 & 207 & 293 & 489 & 223 & 240 & 689 & 701 & 516 & 1048 \\
\hline Domingo-Criollo & 169 & 156 & 420 & 339 & 315 & 540 & 166 & 50 & 477 & 586 & 297 & 728 \\
\hline Pennsylvania & 126 & 126 & 498 & 249 & 258 & 606 & 184 & 217 & 1313 & 627 & 425 & 2194 \\
\hline Average & 145 & 153 & 412 & 285 & 303 & 589 & 154 & 151 & 729 & 511 & 424 & 1147 \\
\hline (average $\mu \mathrm{g} /$ puff) & 17 & 16 & 6 & 34 & 33 & 8 & 18 & 17 & 11 & 60 & 45 & 16 \\
\hline (average $\mu \mathrm{g} /$ liter) & 489 & 470 & 293 & 962 & 935 & 418 & 524 & 476 & 525 & 1714 & 1286 & 800 \\
\hline
\end{tabular}

Key: I: Little cigar, cigar wrapper, II: Little cigar, paper wrapper, III: Large cigar.

a: Sum of phenol, cresols, 2,4- and 2,5-dimethylphenols and p-ethylphenol.

b: Sum of pyridine, $\alpha$-picoline, 2,6-lutidine, $\beta$ - and $\gamma$-picoline, 2,4-lutidine, 3,5- and 3,4-lutidine. 
two types of cigars, for the little cigars ranging from 11 to $16 \%$, whereas for the large cigars, they are notably only 3 to $4 \%$. Currently we are investigating the fate of the leaf nicotine (and other constituents) during smoking of cigars and its distribution in mainstream and sidestream smoke and butt. We are already aware of the role played by tobacco and smoke $\mathrm{pH}$ on the fate of nicotine during smoking. The smoke $\mathrm{pH}$ also influences the ratio of protonated to unprotonated nicotine (21) as will be discussed below.

Other mainstream smoke constituents are also delivered in lower yields from large cigars although not nearly so marked as TPM, nicotine and BaP. In Table 8 , for example, where values for phenols and pyridine are given for the three groups of cigars, we still note a disproportionately low level of smoke constituents generated from the large cigars. On a per cigar basis, large cigars deliver nearly twice the phenols as corresponding little cigars (about seven times would be expected based on tobacco weight), but on a per puff and per liter basis, only about 25 and $50 \%$ respectively, of the levels from little cigars. This delivery of relatively low levels of phenol from large cigars has been noted before in comparison to cigarettes and was also observed for volatile and non-volatile acids $(7,8$, 10, 14, 15). Pyridine, as might ordinarily be expected, on a per cigar scale, appears in the mainstream of large cigars in about five times the amount as that from little cigars, but on a per puff or per liter of smoke basis these differences are less pronounced and for the most part disappear. Similar to cigarette smoke, cigar smoke also contains more than $80 \%$ of pyridine in unprotonated form (pka $=5.19$ ). Also, $\mathrm{HCN}$ values whether per cigar, per puff or per liter appear to be lowest in the smoke of large cigars as indicated by present data in our laboratory $(19,45)$.*

$\mathrm{CO} / \mathrm{CO}_{2}$ : Carbon dioxide and especially carbon monoxide are important indicators of tobacco combustion with regard to completeness of combustion and to biological activity of total smoke. We determined, therefore, their levels in the mainstream smoke. Data for these are given in Table 9 - where the little cigars are considered first. Here we see the effects of the more porous cigarette paper on concentration levels of $\mathrm{CO}$, which are reduced by nearly $50 \%$ in the smoke from the cigars wrapped in cigarette paper, whereas the $\mathrm{CO}_{2} / \mathrm{CO}$ ratio is higher. It appears that oxidation processes are more complete in the cigars wrapped in more porous paper, so that not only dilution by incoming air, but also enhanced oxidation to $\mathrm{CO}_{2}$ contribute to the observed effect (38).

In Table 10, we compare little and large cigars with regard to $\mathrm{CO}$ and $\mathrm{CO}_{2}$ levels, under the conditions described previously, i. e. standard smoking conditions for the little cigars, and cigar smoking conditions for

\footnotetext{
* Note added in proof: Since submission of the manuscript we have obtained data for HCN in mainstream and sidestream smoke of cigars with the recently developed glc method (45). The values and the ratios of HCN in sidestream vs. mainstream are presented in Table 19.
}

the large cigars. Again $\mathrm{CO}$ and $\mathrm{CO}_{2}$ levels are elevated, about threefold for $\mathrm{CO}$, and sevenfold for $\mathrm{CO}_{2}$, per cigar. Perhaps even higher values should have been expected, taking into consideration the respective quantities of tobacco burned. When we compare values obtained on a per puff and per liter basis, we note

Table 9. $\mathrm{CO}$ and $\mathrm{CO}_{2}$ in smoke from little clgars (standard smoking conditions).

\begin{tabular}{|c|c|c|c|c|c|c|}
\hline & \multicolumn{3}{|c|}{$\begin{array}{l}\text { I: With cigar } \\
\text { wrapper }\end{array}$} & \multicolumn{3}{|c|}{$\begin{array}{l}\text { II: With cigarette } \\
\text { wrapper }\end{array}$} \\
\hline & $\mathrm{co}$ & $\mathrm{CO}_{2}$ & $\begin{array}{c}\mathrm{CO}_{2} / \\
\mathrm{CO}\end{array}$ & $\mathrm{CO}$ & $\mathrm{CO}_{2}$ & $\begin{array}{c}\mathrm{CO}_{2} / \\
\mathrm{CO}\end{array}$ \\
\hline & \multicolumn{6}{|c|}{ (mg/cigar) } \\
\hline Puerto-Rico & 43.1 & 81.2 & 1.88 & 22.0 & 75.0 & 3.41 \\
\hline Manila & 40.6 & 65.3 & 1.61 & 25.0 & 76.1 & 3.04 \\
\hline Colombia & 44.1 & 69.5 & 1.58 & 25.5 & 77.4 & 3.04 \\
\hline Domingo-Criollo & 42.9 & 67.1 & 1.56 & 26.6 & 80.0 & 3.01 \\
\hline Pennsylvania & 40.8 & 69.3 & 1.70 & 20.4 & 61.2 & 3.00 \\
\hline \multirow[t]{3}{*}{ Average } & 42.3 & 70.5 & 1.67 & 23.9 & 73.9 & 3.09 \\
\hline & & \multicolumn{5}{|c|}{ Ratios (I/II) } \\
\hline & & & $\mathrm{CO}$ & 1 & \multicolumn{2}{|c|}{$\mathrm{CO}_{2}$} \\
\hline Puerto-Rico & & & 1.96 & & \multicolumn{2}{|l|}{1.08} \\
\hline Manila & & & 1.62 & & \multicolumn{2}{|l|}{0.86} \\
\hline Colombia & & & 1.73 & & \multicolumn{2}{|c|}{0.90} \\
\hline Domingo-Criollo & & & 1.61 & & \multicolumn{2}{|c|}{0.84} \\
\hline Pennsylvania & & & 2.00 & & \multicolumn{2}{|c|}{1.13} \\
\hline Average & \multicolumn{4}{|c|}{1.78} & \multicolumn{2}{|c|}{0.96} \\
\hline
\end{tabular}

Table 10. $\mathrm{CO}$ and $\mathrm{CO}_{2}$ in cigar smoke: Little ve. large clgars.

\begin{tabular}{lrr|c|c|c|c}
\cline { 2 - 7 } & \multicolumn{3}{c|}{$\mathrm{CO}$} & \multicolumn{4}{c}{$\mathrm{CO}_{2}$} \\
\cline { 2 - 8 } & I & III & III/I & I & III & III/I \\
\hline Puerto-Rico & 43.1 & 99 & 2.30 & 81.2 & 464 & 5.71 \\
Manila & 40.6 & 133 & 3.28 & 65.3 & 514 & 7.87 \\
Colombia & 44.1 & 121 & 2.74 & 69.5 & 509 & 7.32 \\
Domingo-Criollo & 42.9 & 118 & 2.75 & 67.1 & 507 & 7.56 \\
Pennsylvania & 40.8 & 119 & 2.92 & 69.3 & 473 & 6.83 \\
\hline Average & 42.3 & 118 & 2.79 & 70.5 & 493 & 6.99 \\
\hline
\end{tabular}

Key: I: Little cigar, cigar wrapper, III: Large cigar.

Table 19. Hydrogen cyanide: Sidestream vs. mainstream levels ( $\mu g /$ cigark). $^{k}$

\begin{tabular}{lcc|c|c}
\cline { 2 - 4 } & $\begin{array}{c}\text { Mainstream } \\
\text { (MS) }\end{array}$ & $\begin{array}{c}\text { Sidestream } \\
\text { (SS) }\end{array}$ & SS/MS \\
\hline Puerto-Rico & 129 & 18 & 0.14 \\
Manila & 94 & 23 & 0.24 \\
Colombia & 214 & 24 & 0.11 \\
Domingo-Criollo & 234 & 28 & 0.12 \\
Pennsylvania & 51 & 33 & 0.65 \\
\hline
\end{tabular}

* $137 \mathrm{~mm}$. 
how disproportionately low the levels of $\mathrm{CO}$ and $\mathrm{CO}_{2}$ are in the smoke of large cigars (Table 11).

When both little and large cigars are smoked under identical cigar smoking conditions, the differences in $\mathrm{CO}$ and $\mathrm{CO}_{2}$ levels are magnified, on a per cigar basis. Large cigars, under these conditions, deliver six times more $\mathrm{CO}$ and ten times more $\mathrm{CO}_{2}$ than the corresponding little cigars. Of course, one should note that the large cigars require about 70 puffs compared to 13 puffs for the little cigars. Furthermore, it is noteworthy that the cigar smoking conditions, in this case, as compared to the standard cigarette smoking conditions, result in lower values for both $\mathrm{CO}$ and $\mathrm{CO}_{2}$ (Table 12).

$p H:$ The $\mathrm{pH}$ characteristics of the cigars were profiled on a puff by puff basis (Fig. I). A profile typical of those obtained for the little cigars is shown in Figure 2. Generally, the $\mathrm{pH}$ starts out relatively low (6.78 to $7.36)$ in initial puffs, and rises to a maximum (7.50 to 8.19) in the final puffs; this occurs under standard

Table 11. CO and $\mathrm{CO}_{2}$ In cigar smoke: Little ve. large clgars.

\begin{tabular}{l|c|c|c|c}
\cline { 2 - 5 } & \multicolumn{2}{c|}{$\mathrm{CO}$} & \multicolumn{3}{c}{$\mathrm{CO}_{2}$} \\
\cline { 2 - 5 } & $\mathrm{I}$ & $\mathrm{III}$ & $\mathrm{I}$ & $\mathrm{III}$ \\
\hline & \multicolumn{4}{c}{ (mg/puff) } \\
Puerto-Rico & 4.8 & 1.5 & 9.1 & 6.8 \\
Manila & 4.9 & 1.8 & 7.8 & 7.0 \\
Colombia & 5.1 & 1.7 & 8.1 & 7.3 \\
Domingo-Criollo & 5.1 & 1.6 & 7.9 & 6.9 \\
Pennsylvania & 5.2 & 1.8 & 8.7 & 7.1 \\
\hline Average & 5.0 & 1.7 & 8.3 & 7.0 \\
\hline ' & & (mg/liter smoke) & \\
Puerto-Rico & 138 & 73 & 260 & 341 \\
Manila & 139 & 91 & 223 & 352 \\
Colombia & 146 & 86 & 230 & 364 \\
Domingo-Criollo & 144 & 80 & 226 & 343 \\
Pennsylvania & 147 & 89 & 250 & 353 \\
\hline Average & 143 & 84 & 238 & 351 \\
\hline
\end{tabular}

Key: 1: Little cigar, clgar wrapper, III: Large cigar.

Table 12. $\mathrm{CO}$ and $\mathrm{CO}_{2}$ in cigar smoke: Little vs. large cigars (under cigar smoking conditions).

\begin{tabular}{l|rr|r|r|r|r}
\cline { 2 - 7 } & \multicolumn{3}{c|}{ CO } & \multicolumn{4}{c}{$\mathrm{CO}_{2}$} \\
\cline { 2 - 8 } & I & III & III/I & I & III & III/1 \\
\hline Puerto-RIco & 20.7 & 99 & 4.8 & 60.7 & 464 & 7.6 \\
Manila & 21.7 & 133 & 6.1 & 50.8 & 514 & 10.1 \\
Colombia & 21.7 & 121 & 5.6 & 52.6 & 509 & 9.7 \\
Domingo-Criollo & 20.9 & 118 & 5.7 & 48.4 & 507 & 10.5 \\
Pennsylvania & 19.3 & 119 & 6.2 & 48.3 & 473 & 9.8 \\
\hline Average & 20.9 & 118 & 5.6 & 52.2 & 493 & 9.4 \\
\hline
\end{tabular}

Key: I: Little cigar, cigar wrapper, III: Large cigar.
Figure 1. pH proflle of the smoke of a large clgar (Manila) obtained under cigar smoking conditions.

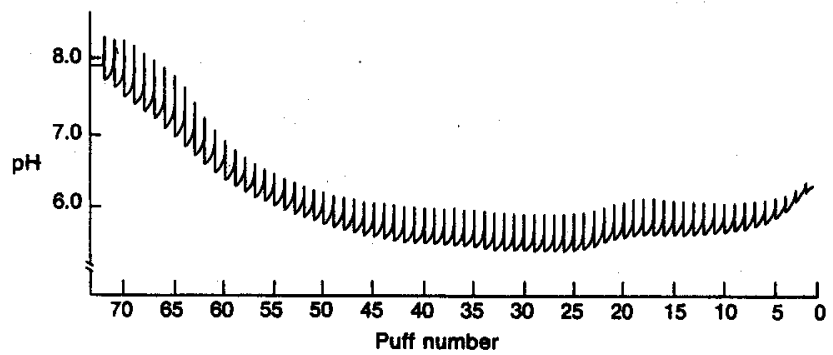

cigarette smoking conditions. Under cigar smoking conditions, somewhat lower $\mathrm{pH}$ values are obtained, although the trend from lower to higher $\mathrm{pH}^{-}$values during the course of puffing is still generally observed. However, in some instances, i. e. in Colombia or Domingo-Criollo cigars, a drop in the $\mathrm{pH}$ profile is noted during intermediate puffs (Tables 15 and 16). As noted previously (16), smoke $\mathrm{pH}$ from genuine tobacco products (assuming no additives) is principally dependent on the tobacco used. The smoke $\mathrm{pH}$ profile of a cigar wrapped in cigarette paper still behaves like that of a cigar and not of a cigarette.

The large cigars smoked according to their specific protocol (in about 70 puffs) produce a smoke $\mathrm{pH}$ profile typified in Figure 1. Like the little cigars, the large cigars initially generate smoke with a relatively low $\mathrm{pH}$, eventually reaching a maximum in the final puffs. Compared to the little cigars, the smoke from the large cigars reaches somewhat higher $\mathrm{pH}$ values, although in early and intermediate puffs, the large cigars exhibit a somewhat lower $\mathrm{pH}$. The $\mathrm{pH}$ is the determining factor for the ratio of protonated to un-

Figure 2. Average pH profile of the smoke of a llttle clgar (Colombla) obtalned under clgarette and clgar smoking conditions.

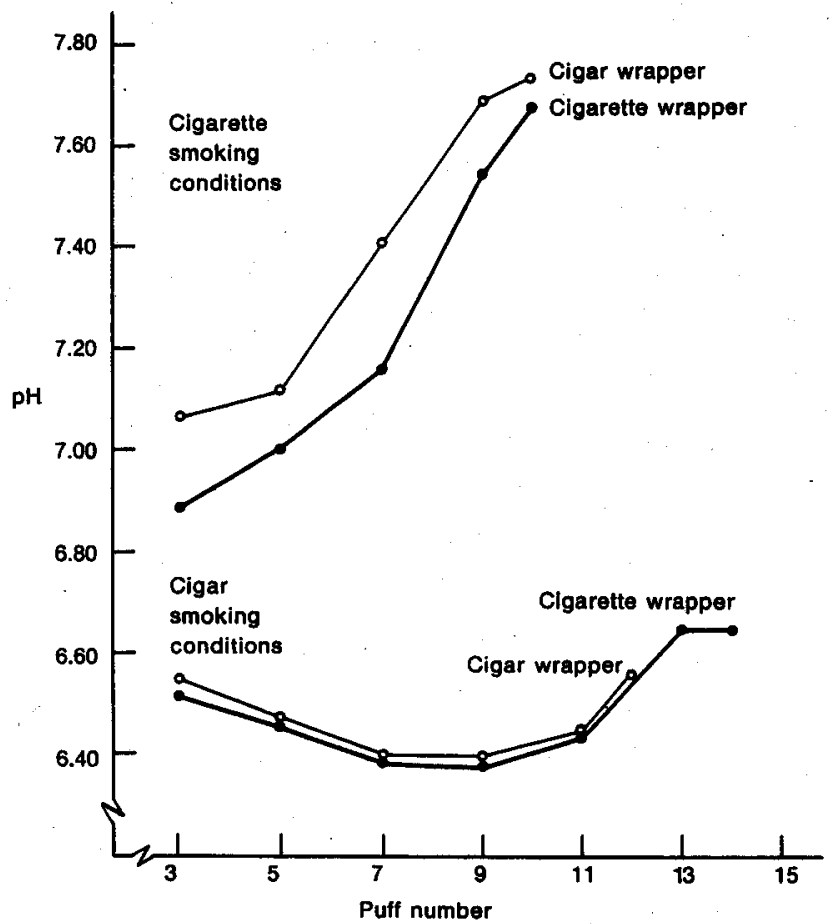


Table 13. Smoke from little clgars - pH of individual puffsa.

\begin{tabular}{|c|c|c|c|c|c|c|c|c|c|c|c|c|}
\hline & \multicolumn{12}{|c|}{ Mainstream - standard smoking conditions } \\
\hline & \multicolumn{2}{|c|}{3} & \multicolumn{2}{|c|}{5} & \multicolumn{2}{|c|}{7} & \multicolumn{2}{|c|}{9} & \multicolumn{2}{|c|}{10} & & \\
\hline & 1 & II & $\mathbf{I}$ & II & 1 & II & 1 & II & 1 & II & & \\
\hline Puerto-Rico & 6.84 & 7.02 & 7.16 & 7.22 & 7.58 & 7.40 & 7.88 & 7.60 & & 7.75 & & \\
\hline Manila & 6.78 & 7.00 & 7.12 & 7.21 & 7.40 & 7.36 & 7.56 & 7.66 & & & & \\
\hline Colombia & 7.07 & 6.88 & 7.12 & 7.00 & 7.41 & 7.16 & 7.69 & 7.55 & & 7.68 & & \\
\hline Domingo-Criollo & 7.22 & 7.16 & 7.52 & 7.41 & 7.78 & 7.60 & 7.93 & 7.80 & & 7.99 & & \\
\hline \multirow[t]{4}{*}{ Pennsylvania } & 7.36 & 7.32 & 7.74 & 7.74 & 8.06 & 8.02 & 8.19 & & & & & \\
\hline & \multicolumn{12}{|c|}{ Mainstream - cigar smoking conditions } \\
\hline & \multicolumn{2}{|c|}{3} & \multicolumn{2}{|c|}{5} & \multicolumn{2}{|c|}{7} & \multicolumn{2}{|c|}{9} & \multicolumn{2}{|c|}{11} & \multicolumn{2}{|c|}{12} \\
\hline & 1 & II & $\mathbf{I}$ & II & $\mathbf{I}$ & II & 1 & II & 1 & II & 1 & 11 \\
\hline Puerto-Rico & 6.84 & 6.79 & 6.99 & 6.96 & 7.06 & 7.00 & 7.12 & 7.04 & 7.32 & 7.12 & $7.58 \mathrm{~b}$ & $7.21 \mathrm{~b}$ \\
\hline Manila & 6.91 & 6.64 & 7.08 & 6.81 & 7.22 & 6.94 & 7.34 & 7.06 & 7.42 & 7.19 & 7.49 & 7.23 \\
\hline Colombia & 6.55 & 6.51 & 6.48 & 6.46 & 6.40 & 6.39 & 6.40 & 6.38 & 6.45 & 6.44 & 6.56 & \\
\hline Domingo-Criollo & 6.74 & 6.63 & 6.65 & 6.76 & 6.72 & 6.86 & 6.84 & 6.98 & 7.08 & 7.10 & & \\
\hline Pennsylvania & 6.86 & 7.20 & 6.99 & 7.38 & 7.06 & 7.66 & 7.14 & 7.82 & $7.28 \mathrm{c}$ & $7.92 \mathrm{c}$ & & \\
\hline
\end{tabular}

a: Puff $\mathrm{pH}=$ mean of maximum and minimum.

c: 10 th puff.

I: Little cigars, cigar wrapper b: 13th puff.

II: Little cigars, paper wrapper

protonated nicotine and other tobacco alkaloids. As demonstrated by Armitage and Turner, unprotonated nicotine is more readily absorbed through mucous membranes than is protonated nicotine, a factor influencing the acute toxicity of nicotine (39).

Cigars vs. Cigarettes: With regard to $\mathrm{pH}$, it is appropriate at this point to compare little cigars and cigarettes as was done previously $(15,16)$ and as is shown in Figure 3. Unlike smoke from little cigars, smoke from cigarettes made of Bright or blended tobacco (major portion Bright tobacco) exhibits a gradual

Table 14. pH of smoke from big cigarse (puff by puff basis).

\begin{tabular}{r|c|c|c|c|c}
\hline $\begin{array}{c}\text { Puff } \\
\text { no. }\end{array}$ & Manila & $\begin{array}{c}\text { Puerto- } \\
\text { Rico }\end{array}$ & $\begin{array}{c}\text { Domingo- } \\
\text { Criollo }\end{array}$ & Colombia & $\begin{array}{c}\text { Penn- } \\
\text { sylvania }\end{array}$ \\
\hline 5 & 6.03 & 5.80 & 6.19 & 5.50 & 6.23 \\
10 & 6.02 & 5.73 & 6.01 & 5.05 & 5.99 \\
15 & 5.98 & 5.72 & 5.95 & 4.71 & 5.91 \\
20 & 5.90 & 5.69 & 5.91 & 4.59 & 5.76 \\
25 & 5.86 & 5.63 & 5.81 & 4.47 & 5.63 \\
30 & 5.89 & 5.53 & 5.71 & 4.55 & 5.60 \\
35 & 5.94 & 5.51 & 5.71 & 4.67 & 5.62 \\
40 & 6.00 & 5.54 & 5.74 & 4.93 & 5.71 \\
45 & 6.06 & 5.62 & 5.83 & 5.29 & 5.87 \\
50 & 6.15 & 5.83 & 5.96 & 5.75 & 6.11 \\
55 & 6.28 & 6.24 & 6.16 & 6.22 & 6.40 \\
60 & 6.51 & 6.81 & 6.50 & 6.81 & 6.81 \\
65 & 6.82 & 7.73 & 6.64 & 7.49 & 7.29 \\
70 & 7.27 & $7.94 \mathrm{~b}$ & 7.09 & $7.96 \mathrm{~b}$ & \\
75 & $7.78 \mathrm{a}$ & & $7.38 \mathrm{a}$ & & \\
\hline
\end{tabular}

a: Puff No. 73.

c: Cigar smoking schedule.
Figure 3. pH profiles of cigar and clgarette smoke (21).
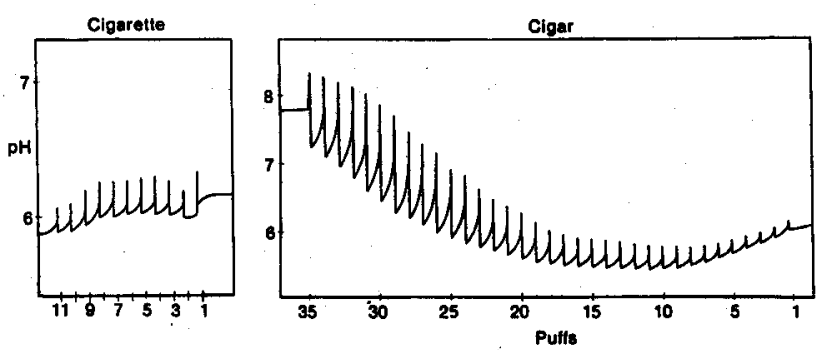

decrease in $\mathrm{pH}$ during successive puffs, usually reaching a minimum in the final puffs. As noted earlier, $\mathrm{pH}$ is a function of the tobacco used, assuming all other factors to be equal, and cigarette tobacco may be distinguished from cigar tobacco by the $\mathrm{pH}$ of the smoke generated. Even when wrapped with cigarette

Table 15. Ammonla: Comparlsons between clgars and cigarette8.

Key: I: Little cigar, cigar wrapper
II: Little cigar, paper wrapper
III: Large clgar

\begin{tabular}{|c|c|c|c|}
\hline & \multicolumn{3}{|c|}{$\mu \mathrm{g} \mathrm{NH} /$ cigar or cigarette } \\
\hline & 1 & II & III \\
\hline Puerto-Rico & 761 & 936 & 661 \\
\hline Manila & 297 & 364 & 158 \\
\hline Colombia & 659 & 804 & 494 \\
\hline Domingo-Criollo & 641 & 699 & 529 \\
\hline Pennsylvania & 607 & 644 & 400 \\
\hline Average & 593 & 689 & 448 \\
\hline
\end{tabular}

Commercial cigarette

(85 mm, non-filter)
134 
Table 16. CO and $\mathrm{CO}_{2}$ : Clgare va. clgarettes.

\begin{tabular}{l|r|r|r|r|r|r}
\cline { 2 - 8 } & \multicolumn{3}{c|}{ CO (mg)* } & \multicolumn{3}{c}{$\mathrm{CO}_{2}$ (mg)* } \\
\cline { 2 - 8 } & A & B & C & A & B & C \\
\hline Little cigar - I & 42 & 5.0 & 143 & 71 & 8.3 & 238 \\
Little cigar - II & 24 & 2.6 & 74 & 74 & 8.0 & 227 \\
Large cigar - III & 118 & 1.7 & 84 & 493 & 7.0 & 351 \\
Cigarette & 18 & 1.6 & 46 & 68 & 6.0 & 172
\end{tabular}

- A: per cigar or clgarette.

B: per puft.

C: per liter.

paper, cigar tobacco gives rise to a $\mathrm{pH}$ profile expected from cigar smoke, as is also seen in smoke from cigarettes made exclusively from Burley tobacco (2I).

Like $\mathrm{pH}$, ammonia levels in smoke seem also to be a function of tobacco type and are characteristically high in the smoke of cigars (vs. cigarettes). According to Johnson, during smoking part of the nitrate in tobacco is reduced to ammonia (40), and since most Burley and cigar tobaccos are relatively high in nitrate, this fact may at least partially explain the elevated ammonia levels in the smoke of little cigars and large cigars (24). Little cigars, for example (Table 15), whether wrapped in cigar wrapper or cigarette paper, give significantly higher values for ammonia than are obtained from a cigarette (593 and $689 \mathrm{mg} / \mathrm{cigar}$ vs. $134 \mathrm{mg} /$ cigarette). Other volatile bases behave similarly.

Cigars also give characteristically high levels of $\mathrm{CO}$ and $\mathrm{CO}_{2}$, although more so for $\mathrm{CO}$ since the porosity of the wrapper is a determining factor for the $\mathrm{CO}$ yield in the smoke $(41,42)$. Use of cigarette paper instead of cigar wrapper results in lowered $\mathrm{CO}$, yet remains above the level of cigarette smoke. $\mathrm{CO}_{2}$, on the other hand, seems to be less affected by the more porous wrapper. Overall, $\mathrm{CO}$ seems more sensitive to changes in "cigarette or cigar engineering" (Table 16).

Large Cigars vs. Little Cigars: As noted, the large cigar compared to the little cigar delivers relatively low concentrations of constituents in mainstream smoke,
Figure 4. Gas chromatogram of vapor phase of clgar smoke (little clgar, Puerto-Rlco tobacco, clgarette wrapper).

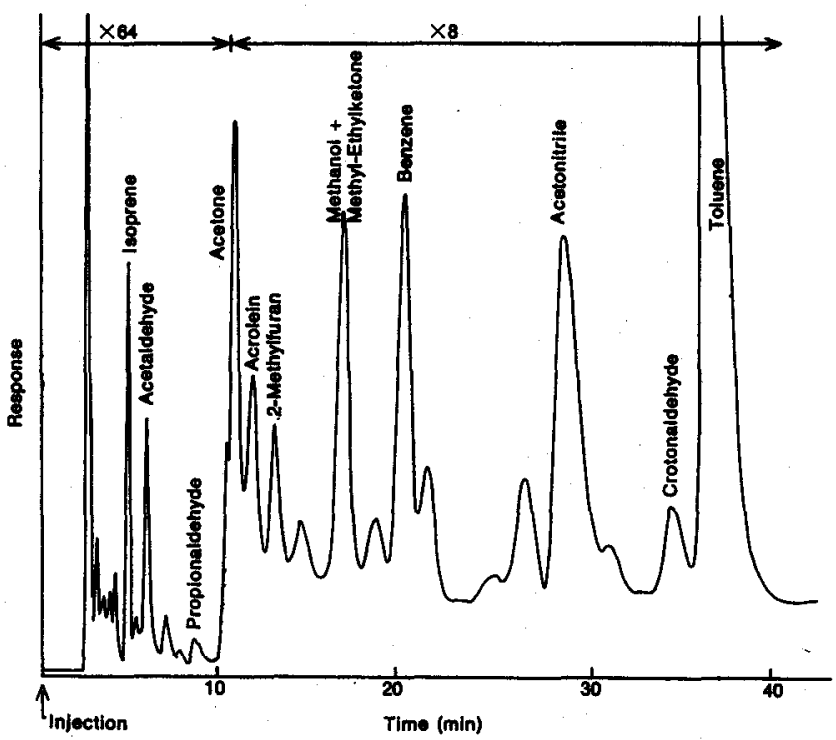

especially in the mainstream particulates. This we noted to be particularly true for TPM, nicotine and $\mathrm{BaP}$ - but is also true for other constituents.

What happens then to cigar tobacco as it is exposed to the elevated temperatures associated with tobacco combustion? If the products generated do not become part of the mainstream particulates, then in order to maintain a material balance, we should expect to find greater concentrations of smoke constituents in the vapor phase (mainstream), and in the sidestream. Table 17 presents data for some of the vapor phase constituents. On a per cigar basis, large cigars generate 6 to 7 times more isoprene, 4 to 5 times more acetaldehyde, and 2 to 7 .times more acrolein than the corresponding little cigars. However, these differences tend to disappear or reverse themselves when one looks at the data on a per puff basis. A gas chromatogram of cigar smoke vapor phase is illustrated in Fig. 4.

As for the sidestream "hypothesis", at the moment we have only $\mathrm{NH}_{3}$ data, and again on a per cigar basis, more $\mathrm{NH}_{3}$ is present in large cigar sidestream than in

Table 17. Gas phase constituents: Little vs. large clgars ( $\mu \mathrm{g} / \mathrm{cigar})^{a}$.

\begin{tabular}{|c|c|c|c|c|c|c|c|c|c|}
\hline & \multicolumn{3}{|c|}{ Isoprene } & \multicolumn{3}{|c|}{ Acetaldehyde } & \multicolumn{3}{|c|}{ Acrolein } \\
\hline & 1 & II & III & 1 & II & III & 1 & II & III \\
\hline Puerto-Rico & 374 & 272 & 2766 & 904 & 804 & 4378 & 39 & 60 & 248 \\
\hline Manila & 282 & 524 & 3083 & 822 & 1160 & 5777 & 21 & 81 & 186 \\
\hline Colombia & 234 & 456 & 3933 & 844 & 1140 & 3228 & 35 & 102 & 183 \\
\hline Domingo-Criollo & 421 & 567 & 2748 & 867 & 1048 & 3632 & 30 & 69 & 227 \\
\hline Pennsylvania & 230 & 429 & 2384 & 708 & 1094 & 5918 & 19 & 74 & 222 \\
\hline Average & 308 & 450 & 2983 & 829 & 1049 & 4587 & 29 & 77 & 213 \\
\hline ( $\mu \mathrm{g} /$ puff [averages]) & 36 & 49 & 42 & 98 & 115 & 65 & 3.4 & 8.4 & 3.0 \\
\hline ( $\mu \mathrm{g} /$ liter [averages]) & 1036 & 1404 & 2118 & 2792 & 3278 & 3270 & 96.4 & 239 & 152 \\
\hline
\end{tabular}

Key: I: Little cigars, clgar wrapper, II: Little cigars, paper wrapper, III: Large clgars.

a: Reference cigarette (85 mm, non-filter): $733 \mu \mathrm{g}$ isoprene, $1372 \mu \mathrm{g}$ acetaldehyde, and $122 \mu \mathrm{g}$ acrolein. 
Table 18. Ammonla: Mainstream vs. sidestream levels ( $\mu$ g/clgar).

\begin{tabular}{lcc|c}
\cline { 2 - 4 } & $\begin{array}{c}\text { Mainstream } \\
\text { (MS) }\end{array}$ & $\begin{array}{c}\text { Sidestream } \\
\text { (SS) }\end{array}$ & SS/MS \\
\hline Little cigar A* & 148 & 6,980 & 47 \\
Little cigar B* & 288 & 11,600 & 40 \\
\hline Cigar** & 158 & 106,000 & 670 \\
\hline
\end{tabular}

- 85 mm, filter (commercial little cigar).

** $137 \mathrm{~mm}$ (Manila).

little cigar sidestream. Furthermore, if one looks at the sidestream to mainstream ratio for $\mathrm{NH}_{3}$, the large cigar value is 670 as compared to 40 for the little cigar (Table 18). This is in line with an earlier finding by Johnson et al. showing the highest sidestream to mainstream ratio for $\mathrm{NH}_{3}$ for the smoke of all Burley cigarettes (43).

It is obvious that to resolve the question of large cigar vs. little cigar, more data are needed, especially a material balance of constituents in mainstream, and sidestream, and in their respective particulate and vapor phases. The data presented indicate, however, that the cigar smoker on a per puff basis is exposed to relatively low levels of certain smoke constituents. On the other hand, large concentrations of constituents, including ammonia, in the sidestream smoke explain at least partially the effects of cigar smoke on nonsmokers, as well as the lingering aroma characteristics associated with cigar smoke and butts. Another factor is the difference in axial and peripheral temperature profiles among various smoking products. A comprehensive study of cigar combustion temperatures indicates that these may differ significantly from those observed in other smoking products (e. g. cigarettes) and that different types of cigars show different combustion profiles as well $(28,44)$.

\section{SUMMARY}

Comparative data have been presented and evaluated on levels of various constituents in five different cigar tobaccos and in the smoke they generate when made into little and large cigars. Generally the large cigars deliver a significantly lower level of mainstream smoke particulates such as TPM, nicotine and benzo(a)pyrene, when compared to the little cigars. On a per cigar basis, however, large cigars (as opposed to little cigars) deliver substantially higher levels of $\mathrm{CO}$ and other gas phase constituents. A higher delivery of ammonia by large cigars is noted in the sidestream smoke. When little cigars are wrapped in cigarette paper, the major effects are lower levels of $\mathrm{CO}$ (reduced by $50 \%$ ). Cigar smoke can be distinguished from cigarette smoke on the basis of pH characteristics, ammonia and $\mathrm{CO}$ levels. Future studies should be concerned with establishing the material balance for components in mainstream and sidestream smoke of little cigars and large cigars.

\section{ZUSAMMENFASSUNG}

Für fünf verschiedene Zigarrentabake und den Rauch, den diese nach Verarbeitung zu kleinen und großen Zigarren erzeugten, wurden von einer Reihe von Inhaltsstoffen vergleichende Daten vorgelegt und ausgewertet. Im Vergleich zu den kleinen Zigarren hatte der Hauptstromrauch der großen Zigarren im allgemeinen einen signifikant niedrigeren Gehalt an Gesamtkondensat, Nikotin und Benz(a)pyren. Im Gegensatz zu den kleinen Zigarren war der Gehalt der großen Zigarren an $\mathrm{CO}$ und anderen Verbindungen der Gasphase je Zigarre jedoch wesentlich größer. Im Nebenstromrauch enthielten die großen Zigarren mehr Ammoniak. Die Umwicklung kleiner Zigarren mit Cigarettenpapier hatte hauptsächlich einen niedrigeren Gehalt an Kohlenmonoxid zur Folge (Verminderung um 50\%). Zigarrenrauch unterscheidet sich von Cigarettenrauch in der $\mathrm{pH}-$ Charakteristik und im Gehalt an Ammoniak und Kohlenmonoxid. Künftige Untersuchungen sollten sich mit der Stoffbilanz von Bestandteilen des Haupt- und $\mathrm{Ne}$ benstromrauches kleiner und großer Zigarren befassen.

\section{RESUME}

On présente et on discute des données comparatives sur les teneurs en différents constituants présents dans cinq différents tabacs pour cigares ainsi que dans la fumée produite par de petits et de grands cigares qui ont été fabriqués avec ces tabacs. En général, le flux principal de fumée d'un grand cigare produit significativement moins de matière particulaire totale, nicotine et benzo(a)pyrène que celui d'un petit cigare. Par cigare, par contre, les grands cigares produisent beaucoup plus de $\mathrm{CO}$ et d'autres constituants de la phase gazeuse. On note une plus grande production d'ammoniaque dans le flux secondaire des grands cigares. Quand de petits cigares sont enroulés dans du papier à cigarettes, l'effet principal est de réduire la production de $\mathrm{CO}$ (de $50 \%$ ). On peut distinguer la fumée de cigare de celle de cigarette par le $\mathrm{pH}$, et la teneur en ammoniaque et en $\mathrm{CO}$. Des études futures devraient essayer d'établir le bilan matière des constituants du flux principal et du flux secondaire pour les grands et les petits cigares.

\section{REFERENCES}

1. Wynder, E. L., and D. Hoffmann: Reduction of tumorigenicity of cigarette smoke: An experimental approach; J. Am. Med. Assoc. 192 (1965) 88-94.

2. Stills, C. D., and R. L. Stedman: Attempts to alter the biological properties of cigarette smoke; Coresta Inf. Bulletin 1965-3, 6-22.

3. Wynder, E. L., and D. Hoffmann: Tobacco and tobacco smoke; Academic Press, 1967, p. 730.

4. Hoffmann, D., and E. L. Wynder: Selective reduction of tumorigenicity of tobacco smoke, II. Experimental approaches; J. Natl. Cancer Inst. 48 (1972) 1855-1868. 
5. Terrell, J. H., and I. Schmeltz: Alteration of cigarette smoke composition, II. Influence of cigarette design; Tobacco Sci. 14 (1970) 82-85.

6. Schmeltz, I: Cigarette smoke: Formation of components and modification of composition by use of additives; Proc., 5th Intern. Tobacco Sci. Cong., Hamburg, 1970, pp. 225-234.

7. Schmeltz, I., and W. S. Schlotzhauer: Volatile acids of cigar smoke; Tobacco Sci. 5 (1961) 92-94.

8. Schmeltz, I., and W. S. Schlotzhauer: Nonvolatile acids of cigar smoke; Tobacco Sci. 6 (1962) 88-89.

9. Schmeltz, I., and R. L. Stedman: Pyridine-3-ol in cigar smoke; Chem. Ind. (London) 1962, 1244-1245.

10. Osman, S., I. Schmeltz, H. C. Higman, and R. L. Stedman: Volatile phenols of cigar smoke; Tobacco Sci. 7 (1963) 141-143.

11. Osman, S., and J. Barson: An aromatic acid fraction of cigar smoke condensate; Phytochem. 5 (1966) $511-515$.

12. Osman, S., and J. Barson: The chemical comparison of four cigar filler tobaccos, I. Preliminary investigation of mainstream and sidestream smoke; Tobacco Sci. 12 (1968) 25-27.

13. Peck, R. L., S. F. Osman, and J. L. Barson: Cigar butt aroma, I. A preliminary study of cigar butt headspace vapors; Tobacco Sci. 13 (1969) 38-39.

1.4. Hoffmann, D., G. Rathkamp, and E. L. Wynder: Comparison of the yields of several selected components in the smoke from different tobacco products; J. Natl. Cancer Inst. 31 (1963) 627-637.

15. Hoffmann, D., and E. L. Wynder: Smoke of cigarettes and little cigars: An analytical comparison; Science 178 (1972) 1197-1199.

16. Hoffmann, D., G. Rathkamp, K. D. Brunnemann, and E. L. Wynder: Chemical studies on tobacco smoke, XXII. On the profile analysis of tobacco smoke; Sci. Total Environ. 2 (1973) 157-171.

17. Pillsbury, H. C., C. C. Bright, K. J. O'Connor, and F. W. Irish: Tar and nicotine in cigarette smoke; J. Assoc. Off. Anal. Chem. 111 (1969) 458-462.

18. International Committee for Cigar Smoke Study: Machine smoking of cigars; Coresta Inf. Bulletin 1974-1, 31-34.

19. Artho, A., and R. Koch: Uber die Bestimmung von Cyanwasserstoff im Cigarettenrauch; Beitr. Tabakforsch. 5 (1969) 58-63.

20. Sensabaugh, A. J., Jr., and R. H. Cundiff: A new method for determining the $\mathrm{pH}$ of whole tobacco smoke; Tobacco Sci. II (1967) 25-30.

21. Brunnemann, K. D., and D. Hoffmann: The $\mathrm{pH}$ of tobacco smoke; Food Cosmet. Toxicol. 12 (1974) 115-124.

22. Hoffmann, D., and E. L. Wynder: Short-term determination of carcinogenic aromatic hydrocarbons; Anal. Chem. 32 (1960) 295.

23. Brunnemann, K. D., and D. Hoffmann: Chemical studies on tobacco smoke, XXIV. A quantitative method for $\mathrm{CO}$ and $\mathrm{CO}_{2}$ in cigarette and cigar smoke; J. Chromatog. Sci. 12 (1974) 70-75.
24. Brunnemann, K. D., and D. Hoffmann: Chemical studies on tobacco smoke, XXXIV. Gas chromatographic determination of ammonia in cigarette smoke and cigar smoke; J. Chromatog. Sci. 13 (1975) 159-163.

25. Hoffmann, D., and G. Rathkamp: Quantitative determination of fluorenes in cigarette smoke and their formation by pyrosynthesis; Anal. Chem. 49 (1972) 899-905.

26. Brunnemann, K. D., and D. Hoffmann: Unpublished.

27. Schmeltz, I., R. L. Stedman, W. J. Chamberlain, and D. Burdick: Composition studies on tobacco, XX. Bases of cigarette smoke; J. Sci. Food Agr. 15 (1964) 774-781.

28. Adams, P. I.: Combustion temperatures in cigars and cigarettes - A comparative study; Tobacco Sci. 12 (1968) 144-150.

29. Rathkamp, G., T. C. Tso, and D. Hoffmann: Chemical Studies on tobacco smoke, XX. Smoke analysis of cigarettes made from Bright tobaccos differing in variety and stalk position; Beitr. Tabakforsch. 7 (1973) 179-189.

30. Cundiff, R. H., and P. C. Markunas: Determination of nicotine, nornicotine and total alkaloids in tobacco; Anal. Chem. 27 (1955) 1650-1653.

31. Schultz, F. J., and A. W. Spears: Determination of moisture in total particulate matter; Tobacco Sci. 10 (1966) 75.

32. Bethmann, M. von, G. Lipp, and H. van Nooy: Feuchtigkeitsbestimmung im Tabak; Beitr. Tabakforsch. 1 (1961) 19-29.

33. Tso, T. C.: Physiology and biochemistry of tobacco plants; Dowden, Hutchinson and Ross, Inc., 1972, p. 393.

34. Lipp, G., and U. Dölberg: Uber die Anwendung der Dimethylphenole zur Bestimmung von Nitrat und Nitrit im Tabak; Beitr. Tabakforsch. 2 (1964) 345-359.

35. Bates, W. W., R. B. Griffith, E. S. Harlow, M. Senkus, and $H$. Wakeham: Determination and reporting of total particulate matter, water in total particulate matter, and nicotine in cigarette smoke; Tobacco Sci. 12 (1968) 192-196.

36. Ogg, C. L., and E. F. Schultz: Collaborative study of the determination of tar and nicotine in cigarette smoke; J. Assoc. Anal. Chemists 53 (1970) 659-672.

37. Brunnemann, K. D., D. Hoffmann, E. L. Wynder, and G. B. Gori: Determination of tar, nicotine, and carbon monoxide in cigarette smoke - A comparison of international smoking conditions; Proceedings, 3rd World Conference on Smoking and Health, New York, N. Y., 1975, in press.

38. Baker, R. R.: The formation of the oxides of carbon by the pyrolysis of tobacco; Beitr. Tabakforsch. 8 (1975) 16-27.

39. Armitage, A. K., and D. M. Turner: Absorption of nicotine in cigarette and cigar smoke through the oral mucosa; Nature 226 (1970) 1231-1232.

40. Johnson, W. R., R. W. Hale, S. L. Clough, and P. H. Chen: The chemistry of the conversion of 
nitrate nitrogen to smoke products; Nature 243 (x973) 223-225.

4. Mumpower, R. C., J. S. Lewis, and G. P. Touey: Determination of carbon monoxide in cigarette smoke by gas dromatography; Tobacco Sci. 6 (x962) $x_{42-145 .}$

42. Imazu, T.: Dilution of gas components of cigarette smoke by diffusion and by air inflow through cigarette paper and perforated paper; Sci. Papers, Central Res. Inst., Japan Monopoly Corp. 1971, 113:139-142.

43. Johnson, W. R., R. W. Hale, J. W. Nedlock, H. J. Grubbs, and D. H. Powell; The distribution of products between mainstream and sidestream smoke; Tobacco Sci. 17 (1973) 141-144.
44. Touey, G. P., and R. C. Mumpower: Combustion zone temperatures in cigars and cigarettes; presented at a meeting of the Cigar Manufacturers' Assoc. of America, Inc., Atlantic City, N. J., Dec. 4-5, 1957.

45. Brunnemann, K. D., L. Yu, and D. Hoffmann: Chemical studies on tobacco smoke, IXL. Gas dromatographic determination of hydrogen cyanide and cyanogen in tobacco smoke; in preparation.

The authors' addresses:

American Health Foundation, Hammond House Road, Valhalla, N. Y., 10595, U.S.A.

Consolidated Cigar Corporation, Glastonbury, Conn., 06033 , U.S.A. 